\title{
CORRECTION
}

Check for updates

Cite this: J. Mater. Chem. C, 2019

7, 15382

DOI: $10.1039 / c 9 t c 90235 j$

rsc.li/materials-c

\section{Correction: Photochromic transparent wood for photo-switchable smart window applications}

\author{
Lihong Wang, Yanjun Liu, Xiyun Zhan, Dan Luo* and Xiaowei Sun
}

Correction for 'Photochromic transparent wood for photo-switchable smart window applications' by Lihong Wang et al., J. Mater. Chem. C, 2019, 7, 8649-8654.

The authors regret an error in Fig. 3a. The correct version of Fig. 3a is given below.
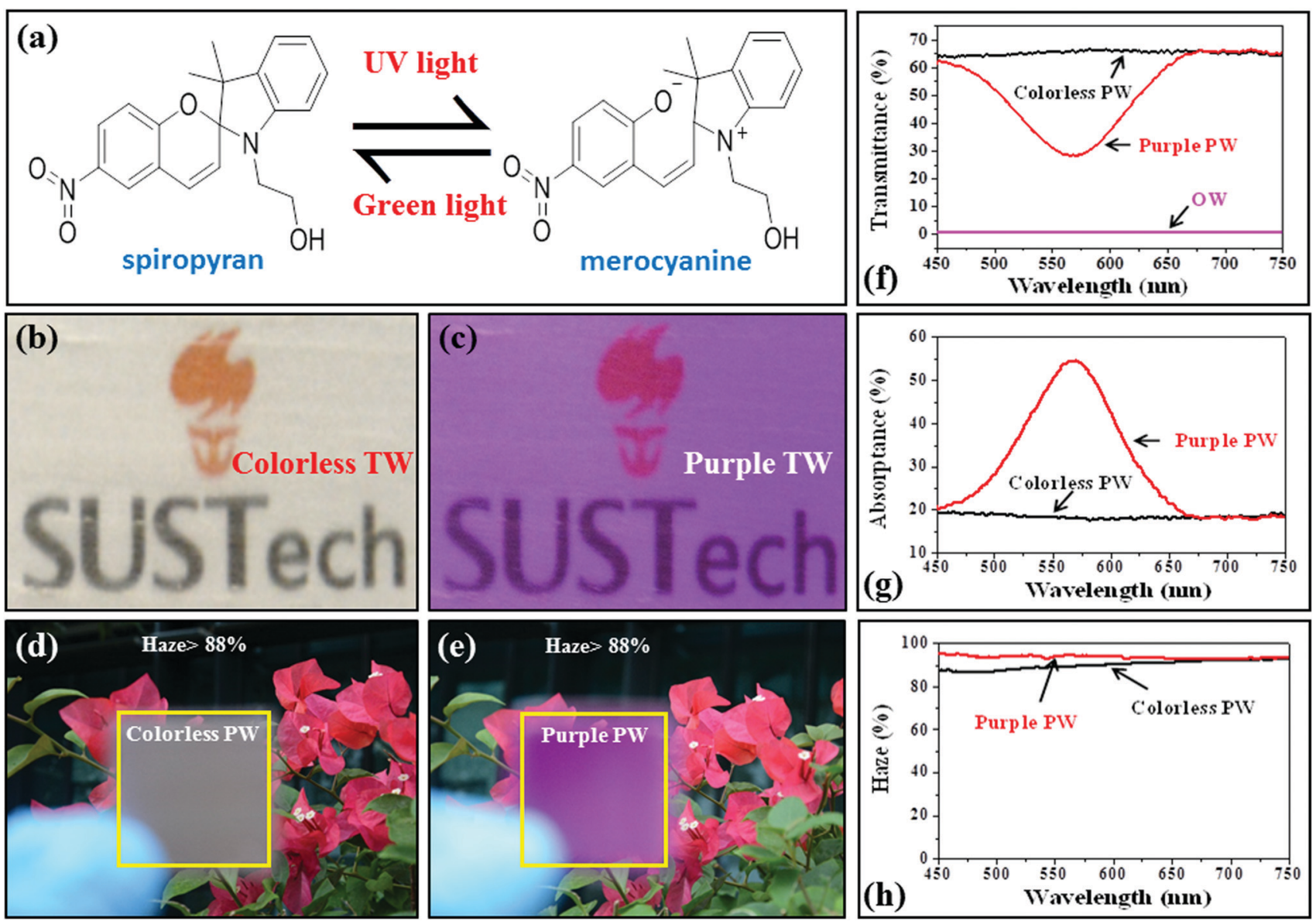

Fig. 3 (a) Chemical structure of spiropyran and merocyanine. The reversible photo switch can be triggered by UV or green light. Photo images of SUSTech logo with (b) colorless PW (spiropyran) and (c) purple PW (merocyanine). Outdoor views of flowers with (d) colorless PW and (e) purple PW. The hazes in both cases are as high as $88 \%$, providing excellent block effects. (f) Transmittance of OW, colorless PW, and purple PW. (g) Absorbance of colorless PW and purple PW. (h) Haze of colorless PW and purple PW.

The Royal Society of Chemistry apologises for these errors and any consequent inconvenience to authors and readers. 